\title{
Unusual DNA-binding properties of the Arabidopsis thaliana WRKY50 transcription factor at target gene promoters
}

\author{
Konstantin Kanofsky ${ }^{1}$ Jendrik Rusche ${ }^{1} \cdot$ Lea Eilert $^{1} \cdot$ Fabian Machens $^{1,2} \cdot$ Reinhard Hehl $^{1}$ (I)
}

Received: 23 June 2020 / Accepted: 21 September 2020 / Published online: 2 October 2020

(c) The Author(s) 2020

\begin{abstract}
Key message WRKY50 from A. thaliana requires WT-boxes at target gene promoters for activation and binding. Abstract Based on the genome-wide prediction of WRKY50 target genes and the similarity of a WRKY50 binding site to WT-boxes in microbe-associated molecular pattern (MAMP)-responsive cis-regulatory modules (CRM), four WT-box containing CRMs from the promoter region of three WRKY50 target genes were investigated for their interaction with WRKY50. These target genes are DJIE, WRKY30 and ATBBE4. Two of the four CRMs, one from DJIE and one from WRKY30, were able to activate reporter gene expression in the presence of WRKY50. Activation requires the WT-boxes GGACTTTT, GGACTTTG from DJIE and GGACTTTC from WRKY30. WRKY50 does not activate a second CRM from WRKY30 and the CRM from ATBBE4, both containing the WT-box TGACTTTT. In vitro gel-shift assays demonstrate WT-box-specific binding of the WRKY50 DNA-binding domain to all four CRMs. This work shows a high flexibility of WRKY50 binding site recognition beyond the classic W-box TTGACC/T.
\end{abstract}

Keywords Electrophoretic mobility shift assay $\cdot$ Parsley protoplasts $\cdot$ Pep25 $\cdot$ Reporter gene $\cdot$ Transcriptional regulation . Transient gene expression

\section{Introduction}

The transcriptional response of plants towards pathogens or MAMPs is mostly carried out by WRKY transcription factors (TFs). The classic WRKY binding site, the W-box, is enriched in promoters of pathogen-responsive genes (Maleck et al. 2000; Rinerson et al. 2015; Chen et al. 2019). In addition to WRKY TFs, other transcription factor families such as AP2/EREBP, bZIP, and MYB also contribute to pathogen-responsive gene expression (Rushton and Somssich 1998; Amorim et al. 2017). All TFs recognize a characteristic DNA binding site motif and the presence of such sequence motifs in a gene promoter allows the prediction

Communicated by Neal Stewart.

Reinhard Hehl

r.hehl@tu-bs.de

1 Institut für Genetik, Technische Universität Braunschweig, Spielmannstr. 7, 38106 Braunschweig, Germany

2 Present Address: Max-Planck-Institut für Molekulare Pflanzenphysiologie, Potsdam Science Park, Am Mühlenberg 1, Golm, 14476 Potsdam, Germany of how the gene is regulated (Hehl and Wingender 2001). To detect such sequences, promoters or gene identification numbers can be submitted to search databases of known regulatory sequences such as TRANSFAC, AGRIS, PlantCare, AthaMap, and PLACE (Higo et al. 1999; Lescot et al. 2002; Matys et al. 2003; Yilmaz et al. 2011; Hehl et al. 2016; Hehl and Bülow 2014). To identify gene groups that may be regulated by the same TF, promoters of co-regulated gene sets can be analysed simultaneously (Galuschka et al. 2007; Hehl and Bülow 2008, 2014). To date, binding sites for almost 1000 of the approximately $2400 \mathrm{TFs}$ of $A$. thaliana have been identified by using mainly high-throughput methods such as DNA Affinity Purification sequencing (DAP-seq) or Protein Binding Microarrays (Perez-Rodriguez et al. 2010; Weirauch et al. 2014; Franco-Zorrilla et al. 2014; O'Malley et al. 2016; Bartlett et al. 2017; Hehl 2017).

In order to discover novel TF-binding sites, pattern recognition programs can be employed, that identify identical sequence patterns in the promoters of co-regulated genes. Examples of such programs include MEME, AlignACE, BioProspector, or CONSENSUS (Bailey and Elkan 1995; Hertz and Stormo 1999; Hughes et al. 2000; Liu et al. 2001). In an earlier study, we applied this approach in combination 
with transient parsley protoplast transformation technology to identify novel MAMP-responsive sequences (Koschmann et al. 2012). This analysis was based on microarray experiment data obtained from the PathoPlant database. Gene groups induced by up to five different MAMPs were identified and the respective promoter regions were analysed by using the binding-site estimation suite of tools (BEST) (Che et al. 2005; Bülow et al. 2007; Koschmann et al. 2012). Motifs generated from these sequences were then classified using the STAMP webserver (Mahony and Benos 2007). Similarities to binding sites of known plant transcription factor families were determined using the AGRIS, PLACE, and AthaMap databases in STAMP (Higo et al. 1999; Davuluri et al. 2003; Steffens et al. 2004). One of the identified motifs bears similarity to WRKY transcription factor (TF) binding sites (Koschmann et al. 2012). The sequences in this motif are characterized by a conserved GACTTT core sequence. The similarity to W-boxes and the prolonged T-stretch led to the designation WT-box which is an 8-bp sequence harbouring the 6-bp core sequence GACTTT (Machens et al. 2014; Kanofsky et al. 2018). The different WT-boxes are characterized by their nucleotides directly adjacent to the GACTTT core sequence and may also contain the W-box TTGACC /T, the classic binding site of WRKY TFs (Rushton et al. 2010; Kanofsky et al. 2017). In some instance the WT-box is part of a cis-regulatory module (CRM) linked to W- and GCC-boxes (Lehmeyer et al. 2016; Kanofsky et al. 2017).

The binding of WRKY TFs to the WT-box was confirmed for different examples by using yeast one-hybrid screenings, transient reporter gene technology, and in vitro gel-shift assays. WRKY70 interacts, for example with the WT-box CGACTTTT (Machens et al. 2014) and also binds to the WT-box AGACTTTT in the SARD1 promoter (Zhou et al. 2017). Also, the WT-box GGACTTTC, present in a cisregulatory module in the promoter of the WRKY3O gene is bound by WRKY26, a transcriptional repressor of this CRM (Kanofsky et al. 2017). In another study which involved a CRM from the promoter of the A. thaliana DJIE gene containing two WT-boxes and a GCC-box, yeast one-hybrid screenings only identified AP2/EREBP transcription factors interacting with the GCC-box (Lehmeyer et al. 2016). No factors binding to the WT-boxes GGACTTTT and GGACTT TG were identified in yeast one-hybrid screenings.

Recently, WRKY50 (At5g26170) was shown to interact with the promoter element GGACTTTTC in the A. thaliana PRI promoter (Hussain et al. 2018b). This promoter element harbours the WT-box core sequence GACTTT. However, WRKY50 was never identified in previous yeast one-hybrid screens with WT-box containing $c i s$-sequences despite using a TF-only prey library (Mitsuda et al. 2010; Lehmeyer et al. 2016; Kanofsky et al. 2017). A recent yeast one-hybrid screen with a WT-box containing cis-sequence from the gene At1g76960 identified WRKY40, but this TF binds to the WT-box adjacent sequence TTTTCTA (Kanofsky et al. 2019).

WRKY50 is involved in the repression of jasmonic acidmediated signalling under low oleic acid conditions (Gao et al. 2011). The WRKY50 encoding gene is a direct in vivo target of WRKY18, 33, and 40 (Birkenbihl et al. 2017). A model was proposed in which the phosphorylation status of WRKY50 associated with the activity of the Arabidopsis Botrytis-induced kinase I (BIKI) regulates jasmonic acid content (Lal et al. 2018). Overexpression of WRKY50 also leads to higher sinapic acid contents in transgenic plants (Hussain et al. 2018a). The target genes of WRKY50 were recently predicted by DAP-seq. DAP-seq identified genomic DNA fragments which can bind in vitro to WRKY50. Based on the frequency and genomic position of these sequences, a total of 10,181 putative WRKY50 target genes were proposed (O'Malley et al. 2016). The large number of WRKY50 target genes is surprising but is consistent with in vitro binding site and binding domain studies that showed and predicted a fairly high variability of WRKY50 binding sites (Brand et al. 2010, 2013). The DAP-seq study confirms $P R 1$ to be a target gene of WRKY50 (O'Malley et al. 2016). Interestingly, the proposed WRKY 50 target genes DJIE (At2g38860), WRKY30 (At5g24110), and ATBBE4 (At1g26390) all harbour WT-boxes in their promoters (Koschmann et al. 2012; Lehmeyer et al. 2016; O’Malley et al. 2016; Kanofsky et al. 2017). This led to the hypothesis that these CRMs may be involved in WRKY50-regulated gene expression.

In the present study, the interaction of WRKY50 with WT-box containing CRMs from the WRKY50 target genes DJIE, WRKY3O and ATBBE4 was investigated by transient reporter gene expression experiments and in vitro gelshift assays. These analyses reveal that WT-boxes, whose sequences deviate from the classic W-box, are required for gene expression regulation and in vitro binding by WRKY50.

\section{Materials and methods}

\section{Plasmid constructs}

The recombinant reporter plasmids harbouring the tetramer of sequence 15 (S15) and S15mut1 through S15mut4 in pBT10GUS-d35SLUC were described previously (Lehmeyer et al. 2016). Also, tetramers of S20, S21, S22, S22mut1, S22mut2, S22mut3, S22mut4, S22mut5, S24, S24mut2, S24mut5, S24mut7, S24mut8, and S24mut9 in pBT10GUS-d35SLUC were described previously (Koschmann et al. 2012; Kanofsky et al. 2017). S15mut13 and S21mut1 through S21 mut5 were synthesized as a monomer with partial SpeI and XbaI sites by Life Technologies (Darmstadt, 
Germany), annealed and ligated into the SpeI/XbaI sites of pBT10GUS-d35SLUC. Tetramerization was performed as described (Sprenger-Haussels and Weisshaar 2000; Rushton et al. 2002). The sequences of the monomers and of all mutations are shown in the figures without the SpeI/XbaI sites.

To construct the effector plasmid expressing WRKY50 (At5g26170), the cDNA for WRKY50 was generated from RNA isolated from A. thaliana Col-0 sprayed with $2 \mathrm{mM}$ salicylic acid (Dong et al. 2003). Eight hours after spraying, RNA was isolated with the 'NucleoSpin RNA Plant' kit (Macherey-Nagel). The reverse transcriptase reaction was performed with the 'RevertAid H Minus First Strand cDNA Synthesis Kit' (Thermo Fisher Scientific, Rockford, IL, USA) on $1 \mu \mathrm{g}$ RNA using oligo(dT) primers. The cDNA was amplified with WRKY50 specific forward and reverse primers 5'-CTTCCCGGGATGAATGATG-3' and 5'-GTC GACTTAGTTCATGCTTGAGT-3' using 'peqGOLD PwoDNA-Polymerase' (PEQLAB, Erlangen Germany) and cloned into pCR4Blunt-TOPO ('Zero Blunt TOPO Cloning Kit for Sequencing', Life Technologies). A SmaI/SalI fragment harbouring the coding region from WRKY50 was inserted into the StuI/SalI site of plasmid pORE-O2-d35SpA (pORE) (Machens et al. 2014). The recombinant plasmid was designated WRKY50-pORE.

For gel-shift assays WRKY50BD was expressed in $E$. coli BL21 using pQE-30 (Qiagen, Hilden, Germany). To amplify the DNA-binding domain (BD) from WRKY50pORE primers 5'-CGCGGATCCCTGCCGACAACCAAA ACAAG-3' and 5'-CGCGTCGACTTAGTTCATGCTTGA GTGATTGTG-3' were used. The amplified fragment was cut with BamHI and SalI and cloned into the BamHI and SalI sites from $\mathrm{pQE}-30$. The resulting plasmid was designated WRKY50BD-pQE30.

Plasmid DNA for protoplast transformation was isolated as described by the manufacturer with the ${ }^{\prime}$ NucleoBond ${ }^{R}$ xtra midi EF' or 'NucleoBond ${ }^{\mathrm{R}}$ xtra maxi kit' (MachereyNagel, Düren, Germany). For all recombinant DNA work, standard protocols were employed (Sambrook and Russell 2001). All cloning products were sequenced by GATC Biotech (Konstanz, Germany). DNA sequences were processed and analysed using the 'CLC Main Workbench' software (CLC Bio, Aarhus, Denmark).

\section{Transient reporter gene expression}

For transient reporter gene expression analysis a parsley (Petroselinum crispum) cell culture was used and protoplasts were freshly prepared for each transformation experiment according to a published protocol (Kanofsky et al. 2016). For co-transformation experiments a TF-expressing effector construct based on pORE-O2-d35S-pA and reporter gene constructs harbouring the cis-regulatory sequences cloned as tetramers upstream of the minimal promoter of the uidA gene in pBT10GUS-d35SLUC (pBT10) were performed as described in Machens et al. (2014) and Lehmeyer et al. (2016). MAMP-responsive reporter gene assays were performed using recombinant $\mathrm{pBT10GUS-d35SLUC}$ reporter gene constructs with or without co-transformation of a TFexpressing effector plasmid into freshly prepared parsley protoplasts. Subsequently the transformed protoplasts were treated with or without the MAMP Pep25. As a positive control, the D-element cloned as a tetramer into pBT10GUSd35SLUC was used (Koschmann et al. 2012). Quantification and normalization of reporter gene expression was done according to a recently published protocol (Kanofsky et al. 2016). All transformations were done at least three times independently with two technical replicates each. The exact number of experiments from which mean values and standard deviations were derived are given in the figure legends. Statistical differences between experiments were determined with a $t$-test. An asterisk in the figures denotes a significance threshold of $\leq 0.05$ between two experimental conditions.

\section{Electrophoretic mobility shift assays}

Recombinant WRKY50BD was expressed in and purified from E. coli BL21 (pREP4) using WRKY50BD-pQE30 as described earlier for WRKY70 and WRKY40 (Machens et al. 2014; Kanofsky et al. 2019). Oligonucleotides were end-labelled with $\mathrm{P}^{32}$ and used as probes in EMSAs (Hartmann Analytic, Braunschweig, Germany). The expression of WRKY50BD in E. coli was induced by adding IPTG to a final concentration of $1 \mathrm{mM}$ at an optical density of 0.6 at $600 \mathrm{~nm}$. After an incubation for $4 \mathrm{~h}$ the culture was precipitated by centrifugation. The bacteria were resuspended in $4 \mathrm{~mL} \mathrm{NPI}-10\left(50 \mathrm{mM} \mathrm{NaH}_{2} \mathrm{PO}_{4}, 300 \mathrm{mM} \mathrm{NaCl}, 10 \mathrm{mM}\right.$ imidazole, $\mathrm{pH}$ 8) per gram cell pellet and Benzoase Nuclease (3 Units/mL, Sigma-Aldrich, München Germany), lysozyme $(1 \mathrm{mg} / \mathrm{mL})$, and 'Halt Protease Inhibitor Cocktail, EDTA free $(100 \times)^{\prime}$ ' $(1 \times$ final concentration, Thermo Fisher Scientific) were added (Machens et al. 2014; Kanofsky et al. 2018). The bacterial suspension was incubated on ice for $30 \mathrm{~min}$. Subsequently, the volume was increased to $15 \mathrm{~mL}$ with NPI-10 and the bacteria were lysed with a French Pressure Cell Press. To purify recombinant WRKY50BD, the 'Chelating Sepharose Fast Flow' agent (GE Healthcare, München, Germany) was used. $1 \mathrm{~mL}$ Ni ions coated Sepharose in NPI-10 and the lysed bacterial cells were incubated for $1 \mathrm{~h}$ at $4{ }^{\circ} \mathrm{C}$. The protein bound Sepharose was precipitated by centrifugation $(500 \mathrm{~g})$ and the pellet was washed with NPI buffer containing increasing concentrations of imidazole $(10 \mathrm{mM}, 20 \mathrm{mM}$, and $30 \mathrm{mM})$ followed by centrifugation and resuspension. In a last step the protein was eluted with $1 \mathrm{~mL}$ NPI-500 (500 mM imidazole) twice. The different fractions were analysed by SDS-Page, Coomassie staining and western blot. Protein concentration was determined 
using Bradford reagent. 4-5 $\mu \mathrm{g}$ of recombinant protein was used in a protein-DNA binding reaction. As binding reaction controls, also a sample with no protein or with $E$. coli protein from a strain containing only the vector was used. Gel electrophoresis, drying of the gel, and exposure to an X-ray film was done as described (Kanofsky et al. 2018). All EMSAs were performed three times. One exemplary result is shown in the figures.

\section{Results}

\section{WRKY50 interacts with WT-box containing cis-regulatory sequences from WRKY50 target genes}

The genes DJIE, ATBBE4, and WRKY30 are proposed target genes of WRKY50 and harbour WT-boxes similar to a WRKY50 binding site in their MAMP-responsive CRMs (Koschmann et al. 2012; Lehmeyer et al. 2016; O’Malley et al. 2016; Kanofsky et al. 2017; Hussain et al. 2018b). Since the identification of DJIE, WRKY3O, and ATBBE4 as target genes for WRKY50 by DAP-seq analysis does not necessarily mean that the WT-box containing CRMs are within the fragments bound by WRKY50, we used the genome browser at the Cistrome database to determine their position. The obtained results confirmed that the WT-box containing CRMs from the proposed target genes DJIE, $A T B B E 4$, and WRKY30 are all present within WRKY50bound DNA fragments (O'Malley et al. 2016). Based on this observation, we asked the question whether WRKY50 can activate reporter gene expression through these CRMs. For this, transient reporter gene expression assays were performed employing a parsley protoplast system. Parsley protoplasts have been used as a well-established, standard system for transient gene expression analysis in all our previous work. Co-transformation experiments were done with a WRKY50 expressing effector plasmid (WRKY50-pORE) and reporter plasmids harbouring four copies of the CRMs upstream of the uidA (GUS) reporter gene in pBT10GUSd35SLUC. As a control, a co-transformation with the empty effector plasmid (pORE) and a reporter plasmid void of cis-regulatory sequences (pBT10) was performed as well. Furthermore, a cis-regulatory sequence (S20) with a WTbox from a gene not predicted to be a WRKY50 target gene (At5g12930) was investigated as well. Following the transformation, GUS reporter gene activity was determined and normalized using a constitutively expressed luciferase gene on the reporter gene plasmid (Kanofsky et al. 2016). Figure 1 shows the result of the transient reporter gene assays (A) and the sequences of the analysed CRMs (B). CRM2-WRKY30 was investigated in the opposite orientation as displayed in Fig. 1. This is consistent with the orientation of CRM2WRKY3O in the WRKY30 promoter (Kanofsky et al. 2017).
The orientation displayed in Fig. 1 and below is chosen for better comparability. As expected, in transient reporter gene assays neither the empty effector plasmid pORE, nor the effector plasmid expressing WRKY50 has an effect on the empty reporter plasmid pBT10 and cis-sequence S20. In the presence of CRM-DJIE (S15) and CRM1-WRKY30 (S24), however, the effector plasmid expressing WRKY50 enhances reporter gene activity (Fig. 1). CRM2-WRKY30 (S22) and CRM-ATBBE4 (S21) do not show significantly altered reporter gene expression in the presence of WRKY50 (Fig. 1). In summary, these data suggest that WT-boxes represent potential targets of WRKY50 mediating gene activation.

\section{WRKY50-activated reporter gene expression requires the WT-boxes GGACTTTT, GGACTTTG and GGACTTTC}

As shown in Fig. 1, WRKY50 can activate reporter gene expression through CRM-DJIE (S15) and CRM1-WRKY30 (S24). To determine if the WT-boxes in these CRMs are required for WRKY50-responsive reporter gene expression, mutations in CRM-DJIE and CRM1-WRKY3O were analysed for their effect on gene upregulation by WRKY50. Figure 2 shows that a single mutation in either of the two WT-boxes and a double mutation in both WT-boxes of the CRM-DJIE abolishes WRKY50-responsive reporter gene expression (S15mut1, S15mut3, and S15mut13). In contrast, a mutation between both WT-boxes and a mutation downstream of the WT-box have no effect on WRKY50-stimulated reporter gene expression (S15mut2 and S15mut4). Taken together, these observations indicate, that both WTboxes are required for WRKY50-activated reporter gene expression. A single WT-box is therefore not sufficient for WRKY50-mediated gene activation.

To further test the hypothesis that the WT-box mediates gene activation through WRKY50, CRM1 of WRKY30 were also tested by targeted mutation. CRM1-WRKY30 harbours one WT-box and two W-box or W-box like sequences. One W-box is complete (TTGACC) while a partial one is located in the opposite orientation and lacks the $\mathrm{T}$ at its $5^{\prime}$ end (TGACC). Figure 3 shows that mutations in both W-boxes (S24mut2) do not impact WRKY50-responsive reporter gene activation compared to the unmutated sequence (S24). This suggests that the WT-box in S24 is sufficient for reporter gene activation in response to WRKY50. Consistent with this notion, a mutation in the WT-box (S24mut5) strongly reduces reporter gene induction. Interestingly, however, gene activity is not fully abolished in this construct. Only mutations in both W-boxes and the WT-box (S24mut7) fully suppress WRKY50-mediated reporter gene activation. This indicates that both W-boxes also contribute to WRKY50activated reporter gene expression. Mutations in both 


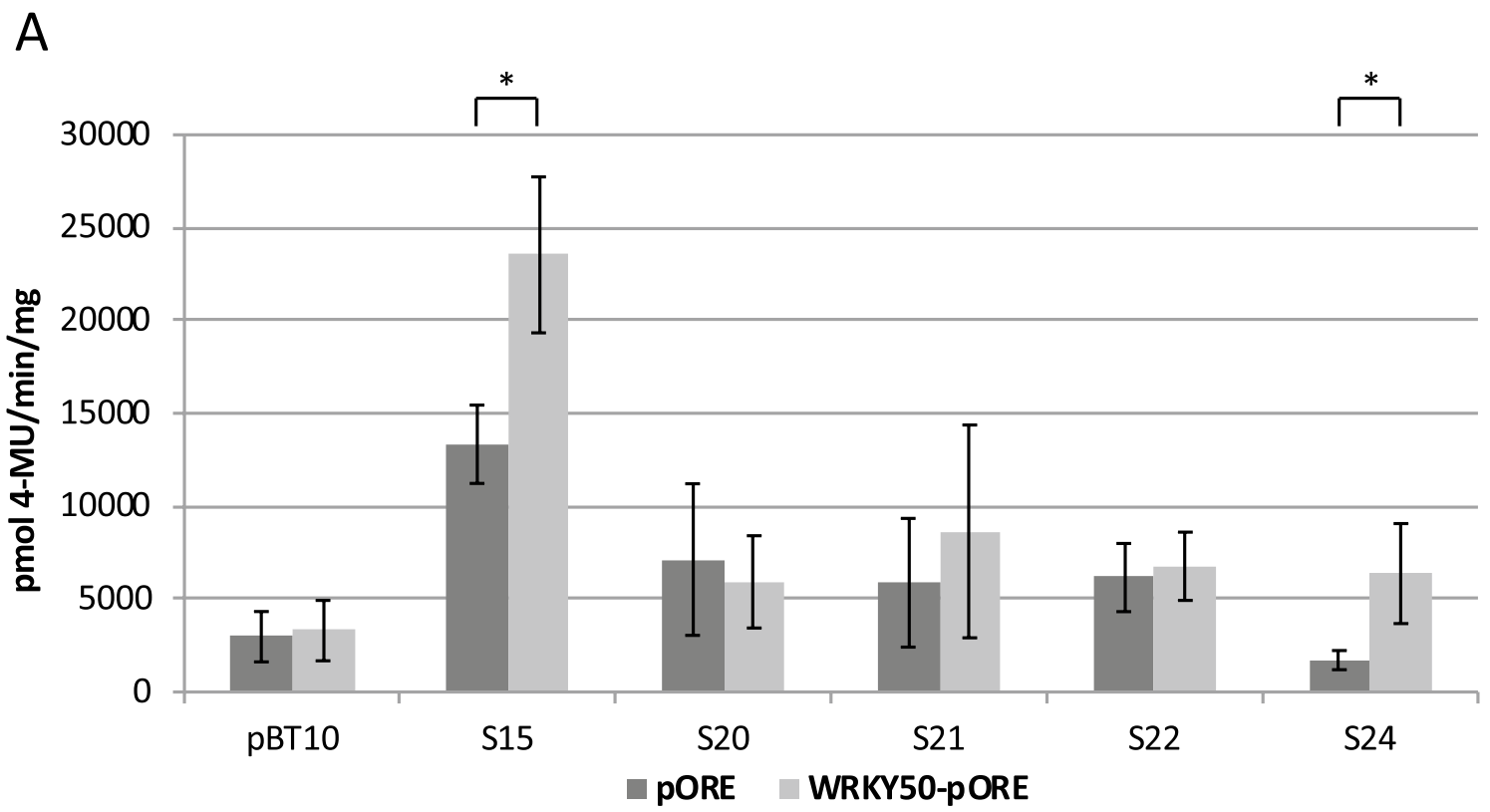

B

$\begin{array}{ll}\text { CRM-DJ1E } & \text { S15 } \\ \text { CRM-At5g12930 } & \text { S20 } \\ \text { CRM-ATBBE4 } & \text { S21 } \\ \text { CRM2-WRKY30 } & \text { S22 } \\ \text { CRM1-WRKY30 } & \text { S24 }\end{array}$

Fig. 1 WRKY50 activates reporter gene expression through WTbox containing CRMs. a Transient reporter gene assays in parsley protoplasts after co-transformation of an effector plasmid expressing WRKY50 (WRKY50-pORE) or the empty vector (pORE) with reporter plasmids harbouring four copies of the indicated sequences upstream of the uidA (GUS) reporter gene. Relative GUS expression and standard deviations were determined from three (S15, S20, S21,

W-boxes and the WT-box (S24mut7) abolish WRKY50mediated reporter gene activation.

In summary, the WT-boxes GGACTTTT and GGACTT TG in CRM-DJIE and the WT-box GGACTTTC in CRM1WRKY30 are required for WRKY50-activated reporter gene expression.

\section{WRKY50 affects MAMP-responsive reporter gene expression by CRM2-WRKY30}

As shown in Fig. 1, WRKY50 does not activate reporter gene expression through CRM-ATBBE4 (S21) and CRM2$W R K Y 30$ (S22). Therefore, it was investigated if co-expression of WRKY50 in the presence and absence of the MAMP Pep25 in parsley protoplasts affects MAMP-responsive reporter gene expression. For this, transient reporter gene expression assays after co-transformation of the WRKY50 expressing effector plasmid (WRKY50-pORE) and reporter
S22, S24), or six (pBT10) independent experiments with technical duplicates, respectively. Sequences S20, S21, and S22 show no statistic significant difference of WRKY50 activation compared to the empty vector (pORE) activation, while S15, and S24 show a statistically significant WRKY50 activation $(p<0.001 ; *)$. b Sequences of the WT-box containing CRMs. The WT-box core sequences are marked in grey

plasmids harbouring four copies of CRM-ATBBE4 (S21) and CRM2-WRKY30 (S22) upstream of the uidA (GUS) reporter gene were performed. Pep25 is an oligopeptide derived from a surface glycoprotein of the phytopathogenic oomycete Phytophthora sojae (Nürnberger et al. 1994; Rushton et al. 1996). As a control, co-transformation with the empty effector plasmid (pORE) and a reporter plasmid void of cis-regulatory sequences (pBT10) or harbouring four copies of the Pep25-responsive D-element were performed as well. The D-element was identified in the parsley $P R 2$ gene promoter (van de Löcht et al. 1990; Kirsch et al. 2000; Rushton et al. 2002). As shown in Fig. 4, the empty vector (pBT10) does not show any Pep25-responsive gene expression while the D-element (D) shows strong Pep25 responsivity. In case of CRM-ATBBE4 (S21) and CRM2-WRKY30 (S22) Pep25-responsive gene expression is observed. In the presence of WRKY50, only Pep25-responsive reporter gene activation of CRM2-WRKY30 but not CRM-ATBBE4 


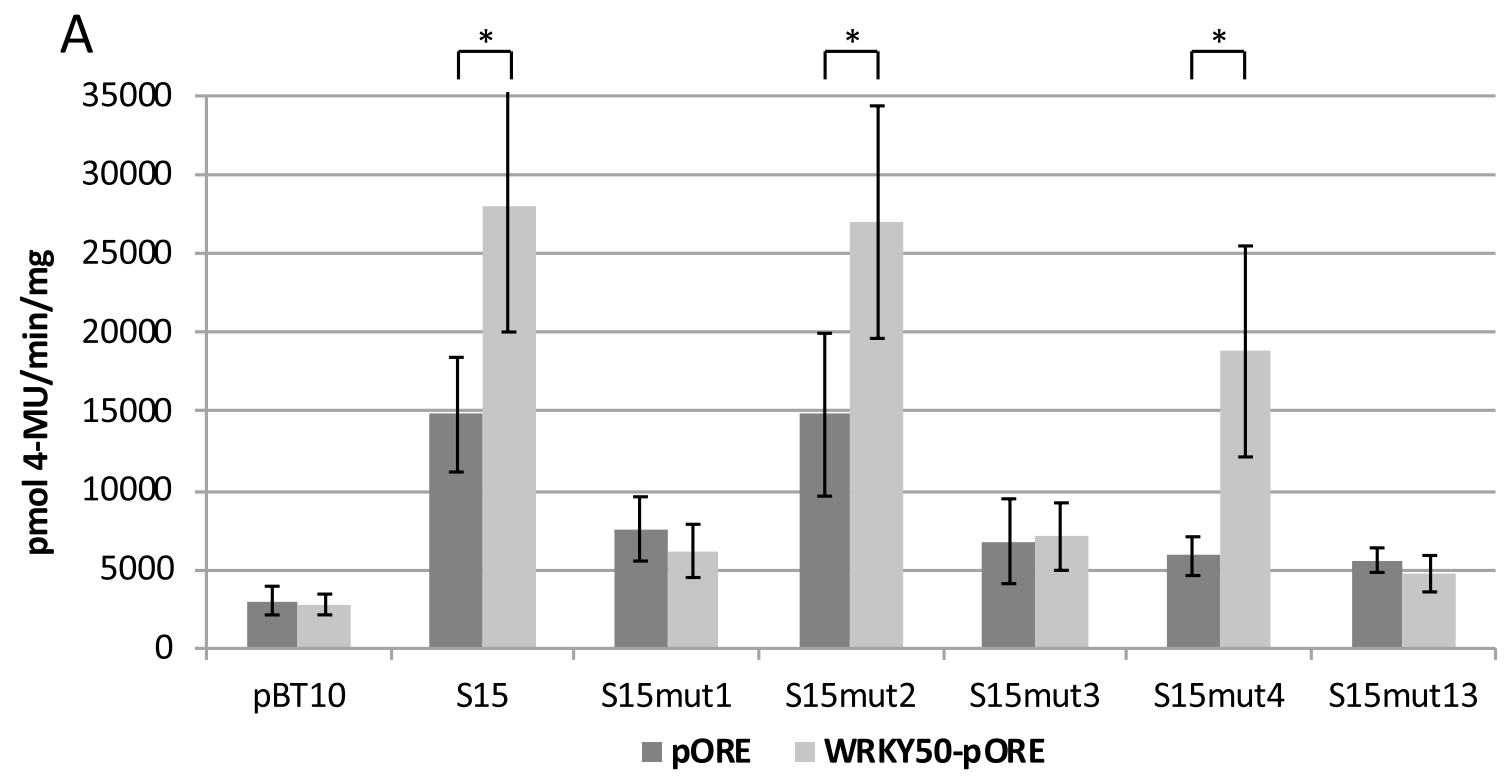

B

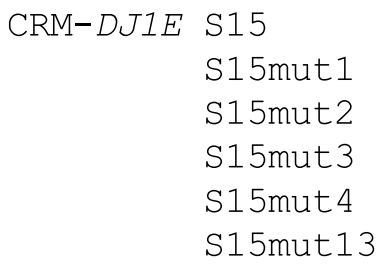

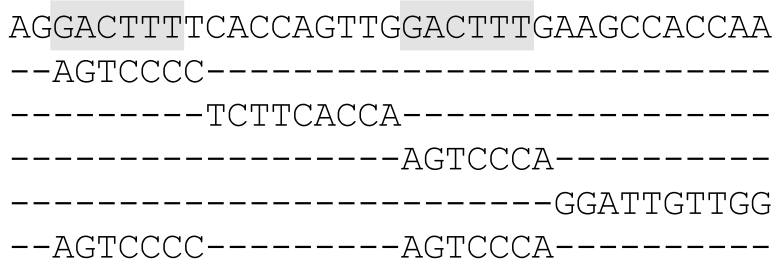

Fig. 2 WRKY50 requires the WT-boxes in CRM-DJ1E for reporter gene activation. a Transient reporter gene assays in parsley protoplasts as described in Fig. 1. Relative GUS expression and standard deviations were determined from three (pBT10, S15mut1, S15mut4, S15mut13), four (S15mut2, S15mut3), or ten (S15) independent experiments with technical duplicates, respectively. Mutations S15mut1, S15mut3, and S15mut13 show no significant statistical

is negatively affected. This may indicate a negative effect of WRKY50 on the MAMP responsivity of CRM2-WRKY30 but does not proof the physical interaction of WRKY50 with either CRM-ATBBE4 or CRM2-WRKY3O.

\section{The WT-boxes in all four CRMs are direct binding sites of WRKY50}

The regulatory sequences CRM-DJ1E (S15) and CRM2WRKY30 (S24) activate reporter gene expression by WRKY50 in transient expression studies (Fig. 1). In contrast, WRKY50 does not activate CRM2-WRKY30 (S22) and CRM-ATBBE4 (S21)-mediated reporter gene expression (Fig. 1). To determine if these four CRMs are directly bound to WRKY50 in vitro and if this binding is WT-box specific, in vitro gel-shift or EMSA experiments were performed with radioactively labelled sequences subjected to differences of WRKY50 activation compared to the empty vector (pORE) activation, while S15 and mutations S15mut2 and S15mut4 show a statistically significant WRKY50 activation $(p<0.001 ; *)$. b Sequence of S15 and of five mutations. The WT-box core sequences are marked in grey. Altered nucleotides in the sequence are shown, unaltered nucleotides are not shown (-)

specific competition experiments by an excess of mutated or unmutated sequences. Figures 5, 6, 7, 8 show the results of these experiments for CRM-DJIE (S15), CRM-ATBBE4 (S21), CRM1-WRKY30 (S24), and CRM2-WRKY30 (S22), respectively. In these experiments the CRMs were radioactively labelled and subjected to binding studies using the DNA-binding domain of WRKY50 (WRKY50BD) purified from E. coli (Materials and methods). As reported before, the full length WRKY50 could not be used for in vitro binding studies (Hussain et al. 2018b). This became evident in EMSA experiments using the 88-bp C-terminal DNA-binding domain and the full length WRKY 50 on an $80 \mathrm{bp} P R 1$ promoter fragment. Only the C-terminal DNA-binding domain produced a shift (Hussain et al. 2018b). In a similar experiment using the cissequence CRM-ATBBE4 (S21), no shift was observed with the full length WRKY50 but only with the WRKY50BD 


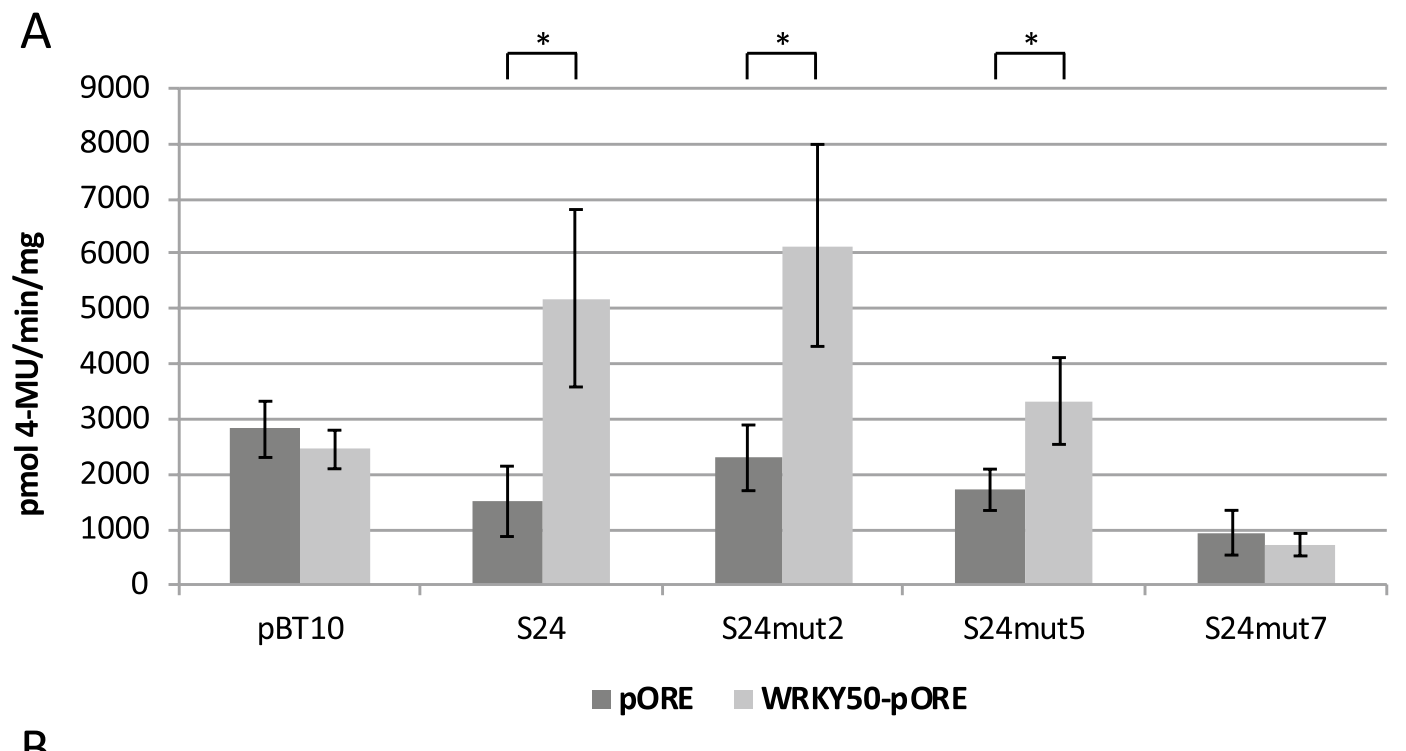

B

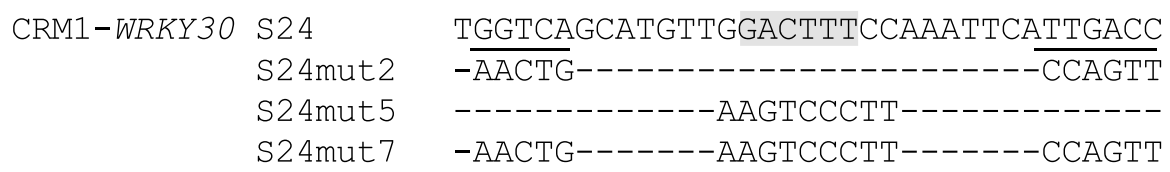

Fig. 3 WRKY50 requires the WT-box in CRM1-WRKY30 for reporter gene activation. a Transient reporter gene assays in parsley protoplasts as described in Fig. 1. Relative GUS expression and standard deviations were determined from three (pBT10, S24mut2, S24mut5, S24mut7), or six (S24) independent experiments with technical duplicates, respectively. Mutation S24mut7 shows no significant statistical difference of WRKY50 activation compared to the

(data not shown). Therefore, WRKY50BD was used for all EMSA experiments in our study.

In case of CRM-DJIE (S15) a shifted complex is observed in the presence of WRKY50BD (Fig. 5, lane 3). This signal can be abolished with an excess of unlabelled S15 (lane 4). Mutations in which one or both WT-boxes are left intact (S15mut1, 2, 3, and 4) can still abolish the shift indicating that one WT-box is sufficient for WRKY50BD binding. If both WT-boxes are mutated (S15mut13), the shift cannot be abolished, indicating that WRKY50BD binds to both WT-boxes (Fig. 5). While for in vitro binding a single WT-box seems to be sufficient, a single WT-box is not sufficient for activating reporter gene expression by WRKY50.

As shown in Fig. 1, CRM-ATBBE4 (S21) does not have an effect on WRKY50-mediated reporter gene activation although CRM-ATBBE4 is derived from a WRKY50 target gene. In contrast to the transient expression analysis, WRKY50BD binds directly to CRM-ATBBE4 (S21) in vitro. Figure 6, lane 3 shows a shifted complex in the presence of WRKY50BD, which can be competed with an excess of unlabelled S21 (lane 4). Mutations affecting the WT-box can no longer abolish complex formation (S21mut1, 3, 4, and empty vector (pORE) activation, while S24 and mutations S24mut2 and S24mut5 show a statistically significant WRKY50 activation $\left(p<0.001 ;^{*}\right)$. b Sequence of S24 and of three mutations. The WTbox core sequence is marked in grey and the $\mathrm{W}$-boxes are underlined. Altered nucleotides in the sequence are shown, unaltered nucleotides are not shown (-)

5) while a mutation downstream of the WT-box (S21mut2) can still abolish complex formation. This shows that WRKY50BD directly binds to the WT-box in S21 in vitro, although no effect on transient reporter gene expression is observed in the presence of WRKY50.

CRM1-WRKY30 (S24) and CRM2-WRKY30 (S22) both affect reporter gene expression in the presence of WRKY50 (Figs. 1, 3, 4). Figure 7 shows WRKY50BD binding to S24 in vitro. Lane 3 shows a shifted complex in the presence of WRKY50BD which can be abolished with an excess of unlabelled S24 (lane 4). Competition with mutated fragments in which the WT-box is intact (S24mut2, 8, and 9) can abolish the shift indicating that the WT-box is sufficient for WRKY50BD binding. With competitors containing a mutated WT-box (S24mut5 and 7), a shift can be observed indicating that sequences with a mutated WT-box no longer bind to WRKY50BD efficiently. The difference in competition efficiency between S24mut5 and S24mut 7 may indicate that a sequence in which both W-boxes are intact (S24mut5) can still partially compete with WRKY50 binding, while a sequence in which all three boxes are mutated (S24mut7) no longer abolishes WRKY50BD binding (Fig. 7). 


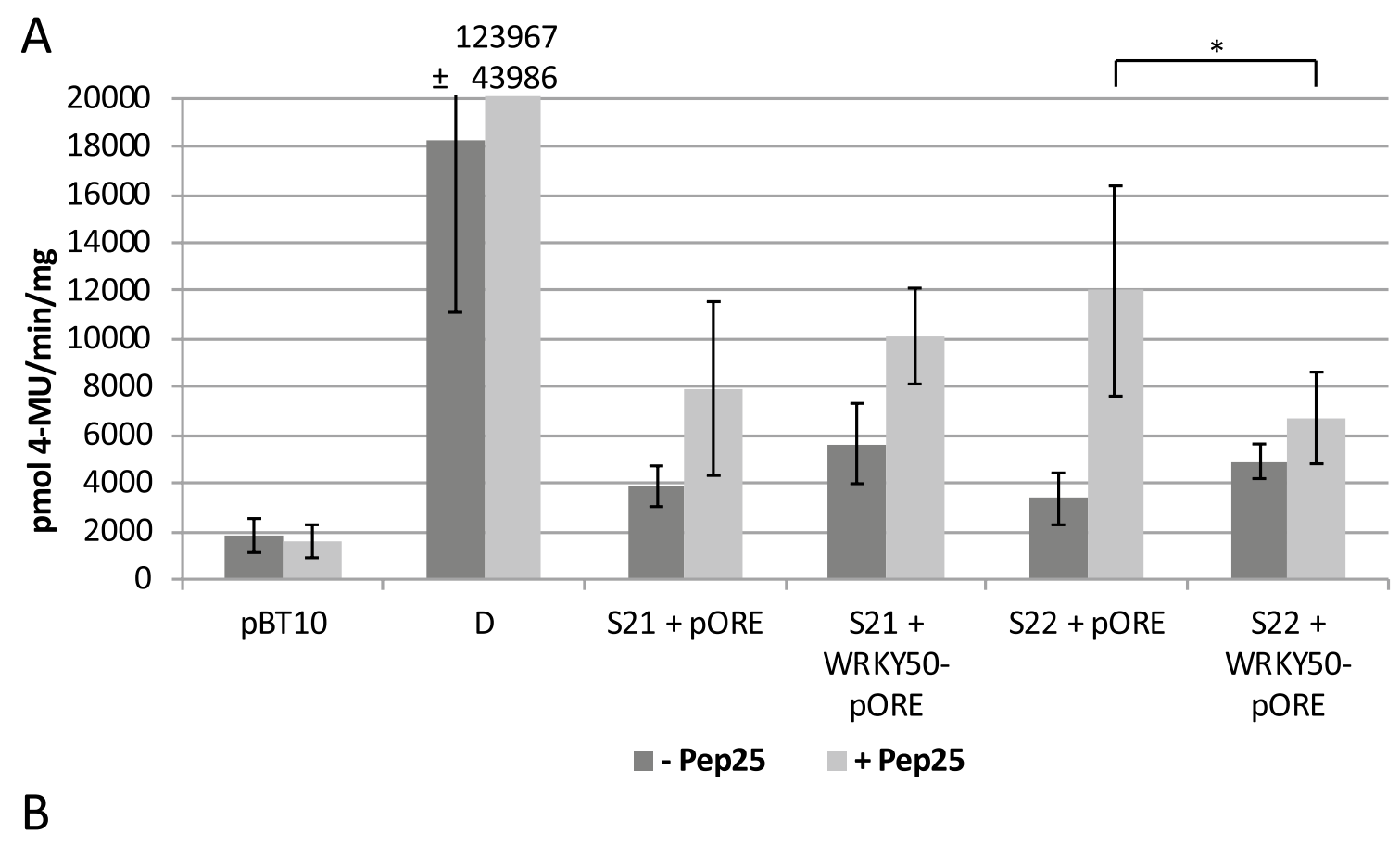

\author{
CRM-ATBBE4 S21 \\ CRM2-WRKY30 S22

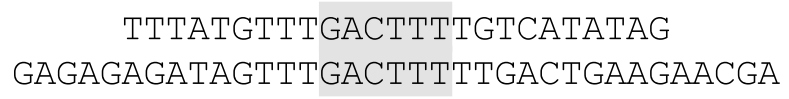

Fig. 4 WRKY50 affects MAMP-responsive reporter gene activation by CRM2-WRKY30. a Transient reporter gene assays in parsley protoplasts after co-transformation of plasmids harbouring CRMATBBE4 (S21) and CRM2-WRKY30 (S22) with a WRKY50 expressing (WRKY50-pORE) or a non-expressing plasmid (pORE) in the presence and absence of Pep25. The empty vector pBT10GUSd35SLUC (pBT10) and this vector containing four copies of the

To investigate WRKY50BD binding to CRM2-WRKY30 (S22) and to determine the binding site specificity of WRKY50 within S22, similar EMSA experiments were performed with S22. Figure 8 shows binding of WRKY50BD to $\mathrm{S} 22$ (lane 3) and that binding can be abolished with an excess of unlabelled competitor (lane 4). Mutations affecting the WT-box (S22mut1-5) can no longer abolish the shift (Fig. 8, lanes 5-9). S22 harbours two complete W-boxes (TTGACT) of which one is part of the WT-box and the other one is adjacent to the WT-box. When a mutation within the adjacent W-box (S22mut1) is used as a competitor, the competition is less efficient indicating a contribution of the W-box in WRKY50 binding (lane 5). However, a mutation leaving the $\mathrm{W}$-box intact, is unable to abolish the shift (S22mut2, lane 6). These results indicate the essential role of the WT-box TGACTTTT for WRKY50BD binding (Fig. 8). In all four cases, CRM-DJ1E (S15), CRM-ATBBE4 (S21), CRM1-WRKY30 (S24), and CRM2-WRKY30 (S22), WRKY50BD directly interacts with the WT-boxes GGA
D-element (D) were used as a negative and positive control for Pep25 induction, respectively. Relative GUS expression and standard deviations were obtained from three (S21), four (S22), or seven (pBT10, D) independent experiments with technical duplicates, respectively. Statistically significant reduction of Pep25 induction in the presence of WRKY50 is indicated with S22 $(p<0.05 ; *)$. b Sequence of S21 and $\mathrm{S} 22$

CTTTT, GGACTTTG, GGACTTTC and TGACTTTT, respectively.

\section{Discussion}

\section{WRKY50 interacts with a CRM from the DJ1E gene to activate reporter gene expression}

The CRM-DJIE was originally identified as a $35 \mathrm{bp}$ long cis-sequence (S15) showing strong MAMP-responsive reporter gene activity in parsley protoplasts (Koschmann et al. 2012). The cis-sequence is located in the upstream region of two gene models of the DJIE gene (At2g38860.1 and At2g38860.3) while also located in the upstream untranslated region of At2g38860.2 (Lamesch et al. 2012). $D J 1 E$ encodes the DJ 1 protein homologue $\mathrm{E}$ which is a member of the $D J 1$ gene family (Lin et al. 2011). The DJ1 gene family of $A$. thaliana contains homologues of the human oncogene DJI (Nagakubo et al. 1997). Mutations 
Fig. 5 Binding of WRKY50BD to CRM-DJIE requires the WT-boxes GGACTTTT and GGACTTTG. a Electrophoretic mobility shift experiment with WRKY50 and the CRM-DJIE (S15) as probe. Lane 1: free probe. Lane 2: free probe plus purified protein extract of E. coli not expressing WRKY50BD. Lane 3: free probe plus purified WRKY50BD. Lane 4: free probe, purified WRKY50BD, and unlabelled competitor (S15) in a 100-fold molar excess. Lanes 5-9: free probe, purified WRKY50BD, and unlabelled mutations S15mut1, S15mut2, S15mut3, S15mut4, and $\mathrm{S} 15$ mut 13, respectively, in a 100 -fold molar excess. A P designates the position of the free probe and a specific DNAprotein complex is marked by an asterisk (*). b The sequence of S15 and of five mutations are shown as in Fig. 2

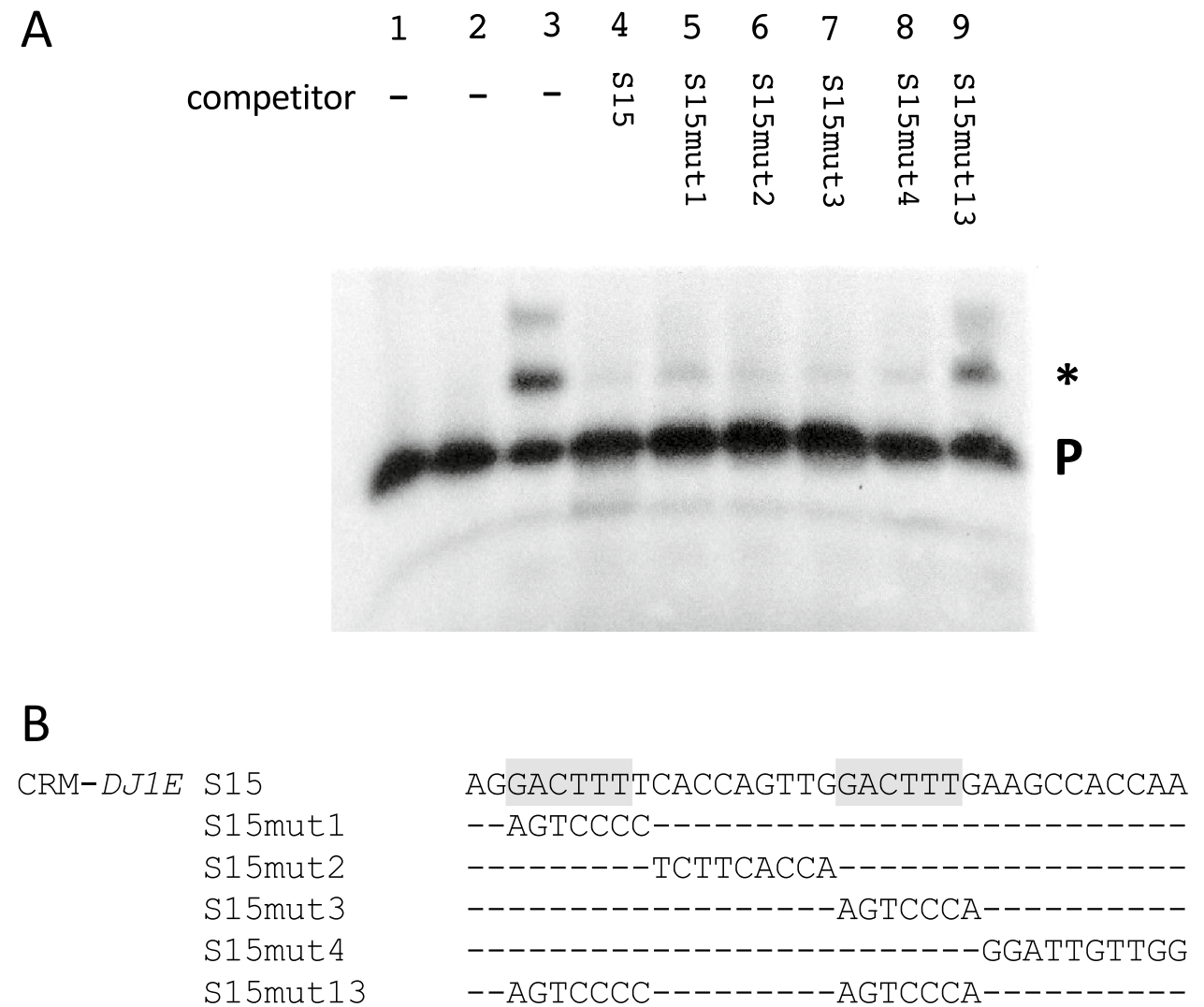

in DJ1 are responsible for the onset of familial Parkinson's disease and DJ1 is involved in antioxidant stress to prevent cell death (Bonifati et al. 2003; Taira et al. 2004). Not much is known about the function of the six A. thaliana DJ1 family members (Seo et al. 2012). The proteins DJ1A, B and D have glyoxalase activity in vitro, but no glyoxalase activity was found for DJ1C, E, and F (Kwon et al. 2013). Similar to its human homologue, DJ1A protects against oxidative stress by activation of cytosolic superoxide dismutase $(\mathrm{Xu}$ et al. 2010). DJIC is essential for chloroplast development (Lin et al. 2011) and DJIE, also designated yellow-leaf-specific gene 5 (YLS5), is upregulated in late senescence stages (Yoshida et al. 2001). A role for DJIE in camalexin and tryptophan biosynthesis pathways was suggested because $D J I E$ is co-expressed with tryptophan biosynthesis pathway genes and with phytoalexin deficient 3 (PAD3) (Wei et al. 2006). Recently, $D J 1 E$ was among a set of genes shown to be responsive to cyclic AMP concentrations (Sabetta et al. 2019). Although the DJIE gene is upregulated by a diverse set of biotrophs and necrotrophs (Zimmermann et al. 2004; Bülow et al. 2007), the mechanism for $D J 1 E$ upregulation has not been elucidated. The analysis of the cis-regulatory module CRM-DJ1E revealed the presence of three cis-regulatory sequences, two WT-boxes and one GCC-box that are all required for MAMP-induced reporter gene expression (Lehmeyer et al. 2016). Yeast one-hybrid screens identified two AP2/EREBP TFs that play antagonistic roles as activator and repressor of CRM-DJIE-regulated reporter gene expression through the GCC-box. However, no TF interacting with the WT-boxes had been identified so far (Lehmeyer et al. 2016). The recent analysis of the PR-I promoter of $A$. thaliana revealed a putative candidate TF for interaction with the WT-boxes of the CRM-DJ1E (Hussain et al. 2018b). WRKY50 was shown to interact with the sequence GGACTTTTC in the $P R-1$ promoter, which was also shown to be involved in 2,6-dichloroisonicotinic acid (INA)-regulated gene expression (Lebel et al. 1998). This sequence is very similar to the WT-boxes in the CRMDJIE (Fig. 2). These findings prompted us to investigate the interaction of WRKY50 with the CRM-DJIE. The obtained data revealed that both WT-boxes are required for WRKY50-activated reporter gene expression (Fig. 2) and for direct binding in gel-shift assays (Fig. 5). The binding of WRKY50 to the WT-boxes GGACTTTT and GGACTTTG seemed to be surprising since the WT-box deviates from the classic WRKY binding site TTGACC/T. However, previous in vitro binding site and binding domain studies showed and proposed a fairly high variability of WRKY50 binding site recognition (Brand et al. 2010, 2013). These earlier studies suggested that WRKY50 seems to require only a conserved GAC core sequence to interact with DNA (Brand et al. 2013). This hypothesis is not supported by our data since 
Fig. 6 Binding of WRKY50BD to CRM-ATBBE4 requires the WT-box TTGACTTTT. a Electrophoretic mobility shift experiment with WRKY50BD and the CRM-ATBBE4 (S21) as probe. Lanes 1-4 are as in Fig. 5 except the labelled probe and the unlabelled competitor (lane 4) is S21. Lanes 5-9: free probe, purified WRKY50BD, and unlabelled mutations S21mut1, S21mut2, S21mut3, S21mut4, and S21mut5, respectively, in a 100 -fold molar excess. A P designates the position of the free probe and a specific DNA-protein complex is marked by an asterisk $(*)$. b The sequence of S21 and of five mutations are shown. The WTbox core sequence is marked in grey. Altered nucleotides in the sequence are shown, unaltered nucleotides are not shown (-)

Fig. 7 Binding of WRKY50BD to CRM1-WRKY30 requires the WT-box GGACTTTC. a Electrophoretic mobility shift experiment with WRKY50BD and the CRM1-WRKY3O (S24) as probe. Lanes 1-4 are as in Fig. 5 except the labelled probe and the unlabelled competitor (lane 4) is S24. Lanes 5-9: free probe, purified WRKY50BD, and unlabelled mutations S24mut2, S24mut5, S24mut7, S24mut8, and S24mut9, respectively, in a 100-fold molar excess. A P designates the position of the free probe and a specific DNA-protein complex is marked by an asterisk (*). b The sequences of S24 and of five mutations are shown. The WT-box core sequence is marked in grey and the two W-boxes are underlined. Altered nucleotides in the sequence are shown, unaltered nucleotides are not shown (-)

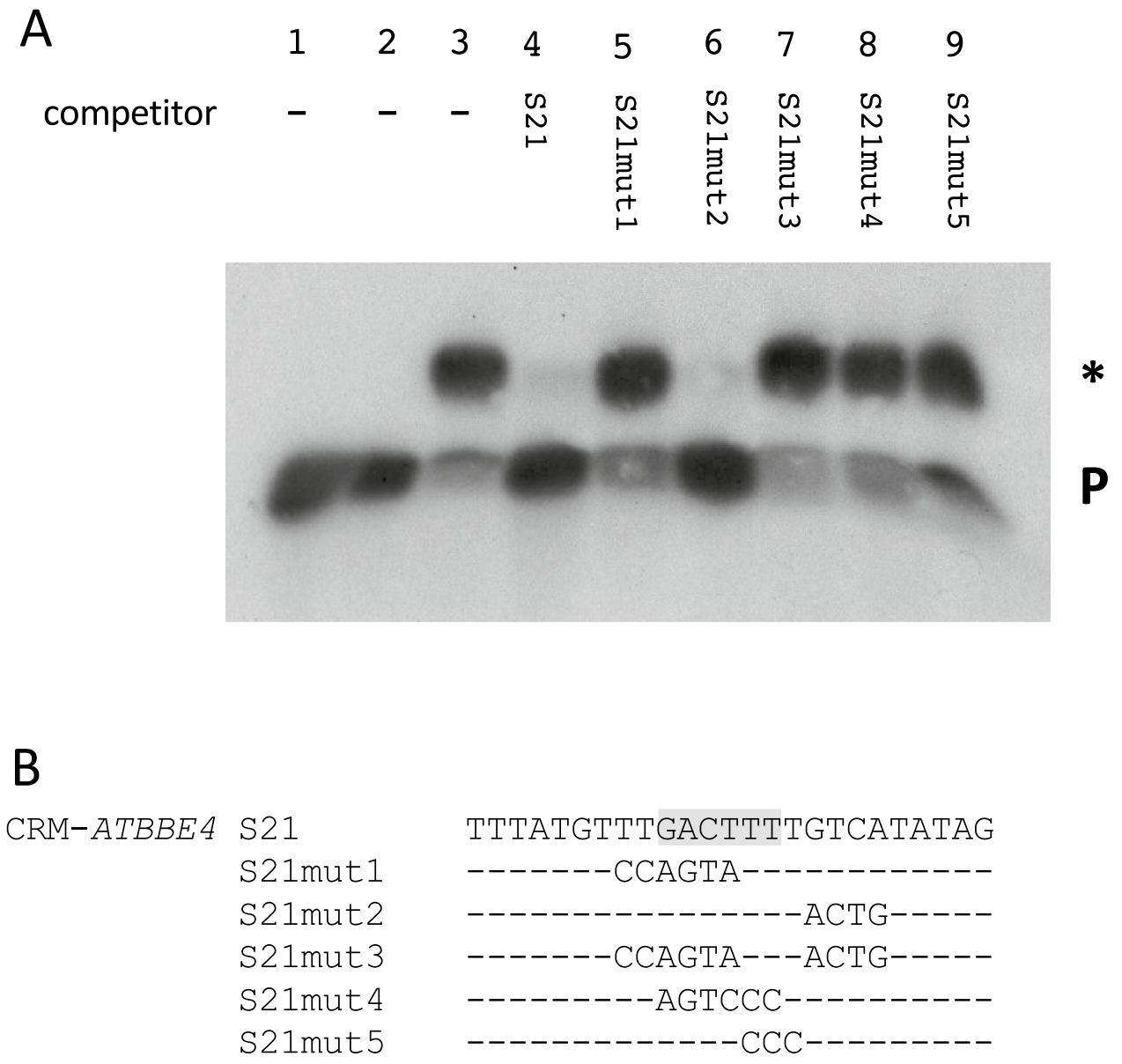

A
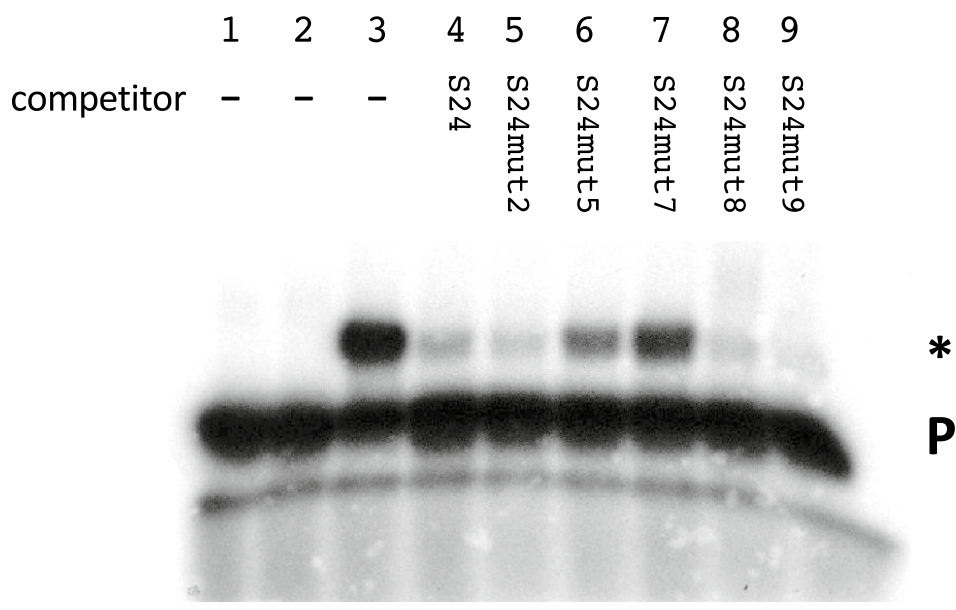

B

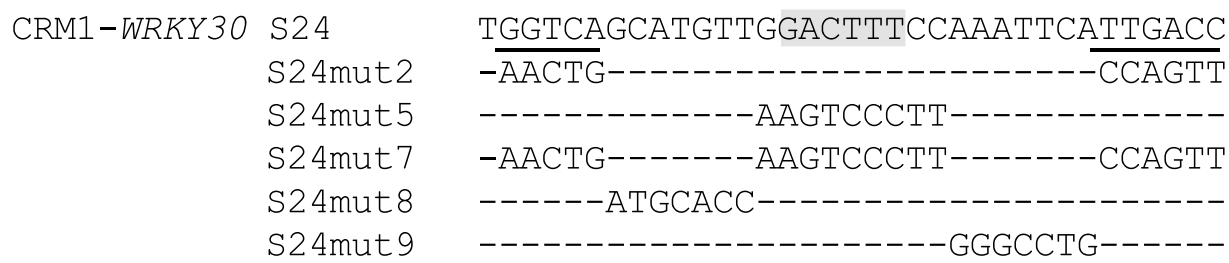


Fig. 8 Binding of WRKY50BD to CRM2-WRKY30 requires the WT-box TTGACTTTT. a Electrophoretic mobility shift experiment with WRKY50BD and the CRM2-WRKY3O (S22) as probe. Lanes 1-4 are as in Fig. 5 except the labelled probe and the unlabelled competitor (lane 4) is S22. Lanes 5-9: free probe, purified WRKY50BD, and unlabelled mutations S22mut1, S22mut2, S22mut3, S22mut4, and S22mut5, respectively, in a 100 -fold molar excess. A P designates the position of the free probe and a specific DNA-protein complex is marked by an asterisk (*). b The sequences of S22 and of five mutations are shown. The WT-box core sequence is marked in grey and the $\mathrm{W}$-boxes are underlined. Altered nucleotides in the sequence are shown, unaltered nucleotides are not shown (-)
A
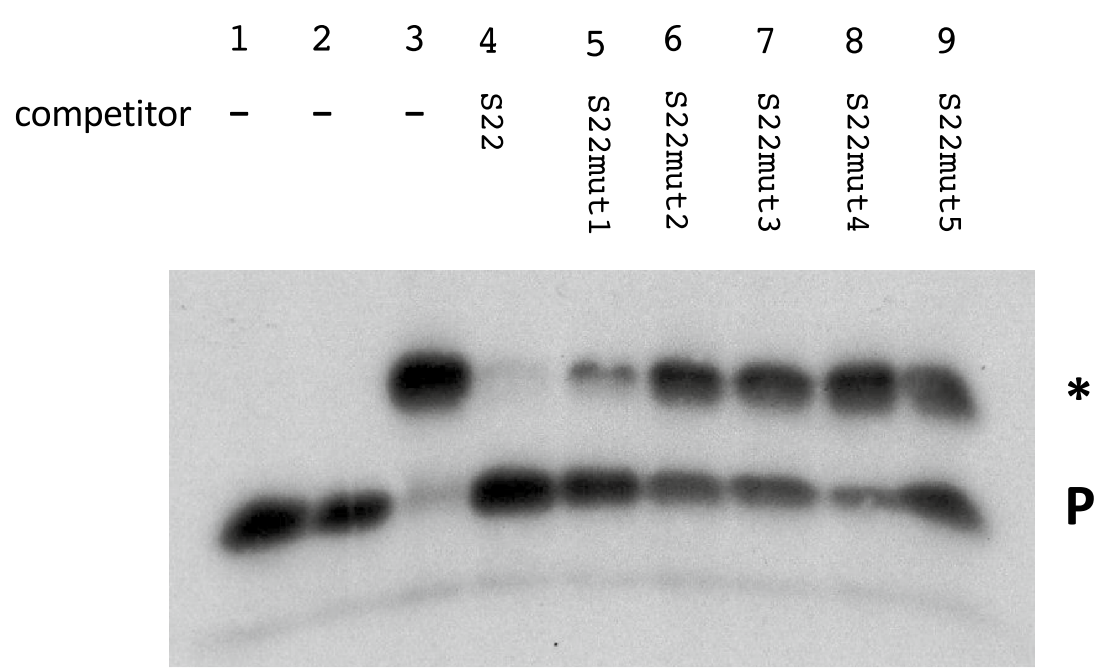

B

$\begin{aligned} & \text { CRM2-WRKY30 } \text { S22 } \\ & \text { S22mut1 } \\ & \text { S22mut2 } \\ & \text { S22mut3 } \\ & \text { S22mut4 } \\ & \text { S22mut5 }\end{aligned}$

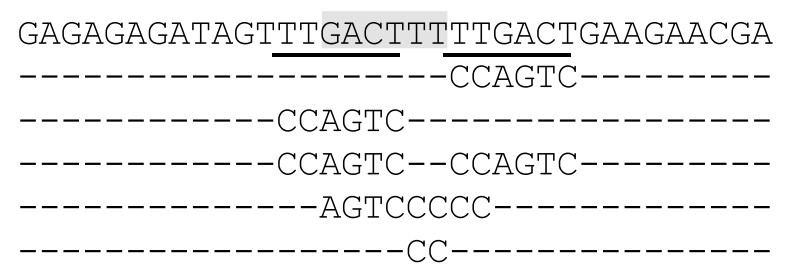

the transitions used for generating mutations also generates a GAC core sequence on the opposite strand. For example, the sequence GACTTT in CRM-DJIE was mutated to yield AGTCCC which maintains a minimal GACT core sequence of a W-box on the opposite strand. Since these mutations abolish WRKY50-activated gene expression, the adjacent nucleotides and/or the orientation of the sequence are important (Fig. 2). Nevertheless, the high variability in binding site recognition is consistent with the large number of 10,181 putative WRKY50 target genes determined by DAP-seq (O'Malley et al. 2016). Among these are the target genes DJIE, ATBBE4, and WRKY30 that are shown here to harbour WRKY50 target sites within CRMs in their upstream regulatory regions.

\section{Interaction of WRKY50 with the CRM-ATBBE4}

The CRM-ATBBE4 was originally identified as S21 in the course of isolating novel MAMP-responsive cis-regulatory sequences (Koschmann et al. 2012). ATBBE4 belongs to a family of berberine bridge enzyme-like (BBE-like) proteins present in plants, fungi, and bacteria (Daniel et al. 2016). The berberine bridge enzyme-like gene family harbours 28 genes of which two catalyse the oxidation of aromatic allylic alcohols to the corresponding aldehydes (Daniel et al. 2015).

Recently, a BBE-like protein was shown to oxidize cellulose oligomers and to play a role in plant immunity (Locci et al. 2019). ATBBE4 encodes a cytoplasmic and extracellular FAD-binding protein with oxidoreductase activity. $A T B B E 4$ is upregulated upon infection by bacterial, fungal, and oomycete pathogens and downregulated in response to abiotic stimuli (Bülow et al. 2007; Hehl et al. 2013). Since the CRM-ATBBE4 confers MAMP-responsive reporter gene expression (Koschmann et al. 2012), this CRM may be responsible for the upregulation of gene expression by biotic stimuli. It is tempting to speculate upon the role of WRKY50 in regulating $A T B B E 4$ gene expression because $A T B B E 4$ is a proposed target gene of WRKY50 (O'Malley et al. 2016) and the CRM-ATBBE4 is bound by WRKY50 in vitro (Fig. 6). However, transient reporter gene expression studies neither show activation nor repression of reporter gene expression in the presence of WRKY50 (Figs. 1, 4). This may be attributed to a low sensitivity of the transient reporter gene expression system. Therefore, it may be interesting to study the effect of WRKY50 on ATBBE4 gene expression in transgenic plants overexpressing or lacking WRKY50.

\section{WRKY30, a target for WRKY50-regulated gene expression}

The two MAMP-responsive CRMs from the WRKY30 promoter were previously analysed in detail (Kanofsky et al. 2017). Using yeast one-hybrid screenings, WRKY26, 
WRKY40, WRKY41, and WRKY70 were identified with CRM1-WRKY30. While WRKY70 is a transcriptional activator of CRM1-WRKY30, WRKY26, WRKY40, and WRKY41 downregulate MAMP-responsive reporter gene expression by CRM1-WRKY30 (Kanofsky et al. 2017). Later it was shown by in vitro gel-shift assays that direct binding of WRKY26 to CRM1-WRKY30 requires the WT-box and both W-boxes (Kanofsky et al. 2018). Based on the results here it is surprising that WRKY50 was not selected in yeast one-hybrid screenings with the CRM1WRKY30. This may be explained by the observation that a full length WRKY50 did not interact with DNA. Based on homology modelling for both full length and truncated proteins, the absence of an interaction with the full length protein may be due to the $\mathrm{N}$-terminal region which possibly impedes the binding of DNA (Hussain et al. 2018b). Because WRKY50 was shown to be regulated by phosphorylation, this may affect its DNA-binding property (Lal et al. 2018).

WRKY30 is a member of the group III family of WRKY TFs. Group III members can be distinguished from members of group I and II by their distinct zinc finger motif (Eulgem et al. 2000). WRKY30 is induced within 2-6 h after inoculation with two Peronospora parasitica isolates and also induced by Blumeria graminis f. sp. hordei (Kalde et al. 2003). Upregulation by these pathogens is not induced by salicylic acid (SA) and independent from SA signalling although it has been found that WRKY30 upregulation during senescence may be partially SA dependent (Besseau et al. 2012). Although upregulation is observed by $P$. parasitica, upregulation does not seem to depend on signalling by the P. parasitica resistance genes RPP2 and RPP4 (Kalde et al. 2003). These conclusions are based on the analysis of mutants defective in SA and RPP2/RPP4 signalling. In contrast, WRKY30 expression depends on chitin signalling. In a chitin receptor kinase mutant (cerk1), WRKY30 is no longer induced indicating WRKY30 is upregulated upon chitin perception (Cao et al. 2014). When WRKY30 induction is analysed for biotic and abiotic stimuli using the database PathoPlant, strong induction of WRKY30 is observed during salt-stress (Bülow et al. 2007). The involvement of WRKY30 in abiotic stress pathways was further substantiated by its overexpression in A. thaliana and wheat (Triticum aestivum). During seed germination in A. thaliana plants overexpressing WRKY30 were more tolerant to oxidative and salinity stress than wild-type plants (Scarpeci et al. 2013). In wheat, overexpression of WRKY30 leads to enhanced heat and drought stress tolerance (El-Esawi et al. 2019). Enhanced heat stress tolerance is conceivable in the light of WRKY30 transcriptional induction by the heat shock factor A4A which itself is a target for mitogen-activated protein kinase 4 phosphorylation (Perez-Salamo et al.
2014; Andrasi et al. 2019). WRKY50 may be a second TF regulating WRKY30 gene expression during abiotic stress.

Author contribution statement RH conceived the idea. KK, JR, LE, FM performed the experiments and analysed the data. RH and KK wrote the manuscript. All authors read and approved the final manuscript.

Acknowledgements We would like to thank Elke Faurie for excellent technical assistance and Lino Wendt for assistance to identify the WRKY50-bound fragments in the Cistrome database. We are grateful to André Fleißner for critical reading of the manuscript. This work was supported by the Federal Ministry of Education and Research, Germany (Hochschulpakt 2020).

Funding Open Access funding enabled and organized by Projekt DEAL.

\section{Compliance with ethical standards}

Conflict of interest The authors declare that they have no conflict of interest.

Open Access This article is licensed under a Creative Commons Attribution 4.0 International License, which permits use, sharing, adaptation, distribution and reproduction in any medium or format, as long as you give appropriate credit to the original author(s) and the source, provide a link to the Creative Commons licence, and indicate if changes were made. The images or other third party material in this article are included in the article's Creative Commons licence, unless indicated otherwise in a credit line to the material. If material is not included in the article's Creative Commons licence and your intended use is not permitted by statutory regulation or exceeds the permitted use, you will need to obtain permission directly from the copyright holder. To view a copy of this licence, visit http://creativecommons.org/licenses/by/4.0/.

\section{References}

Amorim LLB, da Fonseca Dos Santos R, Neto JPB, Guida-Santos M, Crovella S, Benko-Iseppon AM (2017) Transcription factors involved in plant resistance to pathogens. Curr Protein Pept Sci $18: 335-351$

Andrasi N, Rigo G, Zsigmond L, Perez-Salamo I, Papdi C, Klement E, Pettko-Szandtner A, Baba AI, Ayaydin F, Dasari R, Cseplo A, Szabados L (2019) The mitogen-activated protein kinase 4-phosphorylated heat shock factor A4A regulates responses to combined salt and heat stresses. J Exp Bot 70:4903-4918

Bailey TL, Elkan C (1995) The value of prior knowledge in discovering motifs with MEME. Proc Int Conf Intell Syst Mol Biol 3:21-29

Bartlett A, O'Malley RC, Huang SC, Galli M, Nery JR, Gallavotti A, Ecker JR (2017) Mapping genome-wide transcription-factor binding sites using DAP-seq. Nat Protoc 12:1659-1672

Besseau S, Li J, Palva ET (2012) WRKY54 and WRKY70 co-operate as negative regulators of leaf senescence in Arabidopsis thaliana. J Exp Bot 63:2667-2679

Birkenbihl RP, Kracher B, Somssich IE (2017) Induced genome-wide binding of three Arabidopsis WRKY transcription factors during early MAMP-triggered immunity. Plant Cell 29:20-38 
Bonifati V, Rizzu P, van Baren MJ, Schaap O, Breedveld GJ, Krieger E, Dekker MC, Squitieri F, Ibanez P, Joosse M, van Dongen JW, Vanacore N, van Swieten JC, Brice A, Meco G, van Duijn CM, Oostra BA, Heutink P (2003) Mutations in the DJ-1 gene associated with autosomal recessive early-onset parkinsonism. Science 299:256-259

Brand LH, Kirchler T, Hummel S, Chaban C, Wanke D (2010) DPIELISA: a fast and versatile method to specify the binding of plant transcription factors to DNA in vitro. Plant Methods 6:25

Brand LH, Fischer NM, Harter K, Kohlbacher O, Wanke D (2013) Elucidating the evolutionary conserved DNA-binding specificities of WRKY transcription factors by molecular dynamics and in vitro binding assays. Nucleic Acids Res 41:9764-9778

Bülow L, Schindler M, Hehl R (2007) PathoPlant: a platform for microarray expression data to analyze co-regulated genes involved in plant defense responses. Nucleic Acids Res 35:D841-D845

Cao Y, Liang Y, Tanaka K, Nguyen CT, Jedrzejczak RP, Joachimiak A, Stacey G (2014) The kinase LYK5 is a major chitin receptor in Arabidopsis and forms a chitin-induced complex with related kinase CERK1. Elife 3:e03766

Che D, Jensen S, Cai L, Liu JS (2005) BEST: binding-site estimation suite of tools. Bioinformatics 21:2909-2911

Chen X, Li C, Wang H, Guo Z (2019) WRKY transcription factors: evolution, binding, and action. Phytopathol Res 1:13

Daniel B, Pavkov-Keller T, Steiner B, Dordic A, Gutmann A, Nidetzky B, Sensen CW, van der Graaff E, Wallner S, Gruber K, Macheroux P (2015) Oxidation of monolignols by members of the berberine bridge enzyme family suggests a role in plant cell wall metabolism. J Biol Chem 290:18770-18781

Daniel B, Wallner S, Steiner B, Oberdorfer G, Kumar P, van der Graaff E, Roitsch T, Sensen CW, Gruber K, Macheroux P (2016) Structure of a berberine bridge enzyme-like enzyme with an active site specific to the plant family Brassicaceae. PLoS One 11:e0156892

Davuluri RV, Sun H, Palaniswamy SK, Matthews N, Molina C, Kurtz M, Grotewold E (2003) AGRIS: Arabidopsis gene regulatory information server, an information resource of Arabidopsis cisregulatory elements and transcription factors. BMC Bioinformatics $4: 25$

Dong J, Chen C, Chen Z (2003) Expression profiles of the Arabidopsis WRKY gene superfamily during plant defense response. Plant Mol Biol 51:21-37

El-Esawi MA, Al-Ghamdi AA, Ali HM, Ahmad M (2019) Overexpression of AtWRKY30 transcription factor enhances heat and drought stress tolerance in wheat (Triticum aestivum L.). Genes (Basel) 10:163

Eulgem T, Rushton PJ, Robatzek S, Somssich IE (2000) The WRKY superfamily of plant transcription factors. Trends Plant Sci 5:199-206

Franco-Zorrilla JM, Lopez-Vidriero I, Carrasco JL, Godoy M, Vera P, Solano R (2014) DNA-binding specificities of plant transcription factors and their potential to define target genes. Proc Natl Acad Sci USA 111:2367-2372

Galuschka C, Schindler M, Bülow L, Hehl R (2007) AthaMap webtools for the analysis and identification of co-regulated genes. Nucleic Acids Res 35:D857-D862

Gao QM, Venugopal S, Navarre D, Kachroo A (2011) Low oleic acidderived repression of jasmonic acid-inducible defense responses requires the WRKY50 and WRKY51 proteins. Plant Physiol 155:464-476

Hehl R (2017) From experiment-driven database analyses to databasedriven experiments in Arabidopsis thaliana transcription factor research. Plant Sci 262:141-147

Hehl R, Bülow L (2008) Internet resources for gene expression analysis in Arabidopsis thaliana. Curr Genomics 9:375-380
Hehl R, Bülow L (2014) AthaMap web tools for the analysis of transcriptional and posttranscriptional regulation of gene expression in Arabidopsis thaliana. Methods Mol Biol 1158:139-156

Hehl R, Wingender E (2001) Database-assisted promoter analysis. Trends Plant Sci 6:251-255

Hehl R, Bolívar JC, Koschmann J, Brill Y, Bülow L (2013) Databases and web-tools for gene expression analysis in Arabidopsis thaliana. In: Neri C (ed) Advances in genome science: probing intracellular regulation, vol 2. Bentham Science Publishers, Sharjah, pp 176-193. https://doi.org/10.2174/97816080575661130201

Hehl R, Norval L, Romanov A, Bulow L (2016) Boosting AthaMap database content with data from protein binding microarrays. Plant Cell Physiol 57:e4

Hertz GZ, Stormo GD (1999) Identifying DNA and protein patterns with statistically significant alignments of multiple sequences. Bioinformatics 15:563-577

Higo K, Ugawa Y, Iwamoto M, Korenaga T (1999) Plant cis-acting regulatory DNA elements (PLACE) database: 1999. Nucleic Acids Res 27:297-300

Hughes JD, Estep PW, Tavazoie S, Church GM (2000) Computational identification of cis-regulatory elements associated with groups of functionally related genes in Saccharomyces cerevisiae. J Mol Biol 296:1205-1214

Hussain RMF, Kim HK, Khurshid M, Akhtar MT, Linthorst HJM (2018a) Overexpression of AtWRKY50 is correlated with enhanced production of sinapic derivatives in Arabidopsis. Metabolomics 14:25

Hussain RMF, Sheikh AH, Haider I, Quareshy M, Linthorst HJM (2018b) Arabidopsis WRKY50 and TGA transcription factors synergistically activate expression of PR1. Front Plant Sci 9:930

Kalde M, Barth M, Somssich IE, Lippok B (2003) Members of the Arabidopsis WRKY group III transcription factors are part of different plant defense signaling pathways. Mol Plant Microbe Interact 16:295-305

Kanofsky K, Lehmeyer M, Schulze J, Hehl R (2016) Analysis of microbe-associated molecular pattern-responsive synthetic promoters with the parsley protoplast system. Methods Mol Biol 1482:163-174

Kanofsky K, Bahlmann AK, Hehl R, Dong DX (2017) Combinatorial requirement of W- and WT-boxes in microbe-associated molecular pattern-responsive synthetic promoters. Plant Cell Rep 36:971-986

Kanofsky K, Strauch CJ, Sandmann A, Moller A, Hehl R (2018) Transcription factors involved in basal immunity in mammals and plants interact with the same MAMP-responsive cis-sequence from Arabidopsis thaliana. Plant Mol Biol 98:565-578

Kanofsky K, Riggers J, Staar M, Strauch CJ, Arndt LC, Hehl R (2019) A strong NF-kappaB p65 responsive cis-regulatory sequence from Arabidopsis thaliana interacts with WRKY40. Plant Cell Rep 38:1139-1150

Kirsch C, Takamiya-Wik M, Schmelzer E, Hahlbrock K, Somssich IE (2000) A novel regulatory element involved in rapid activation of parsley ELI7 gene family members by fungal elicitor or pathogen infection. Mol Plant Pathol 1:243-251

Koschmann J, Machens F, Becker M, Niemeyer J, Schulze J, Bülow L, Stahl DJ, Hehl R (2012) Integration of bioinformatics and synthetic promoters leads to the discovery of novel elicitorresponsive cis-regulatory sequences in Arabidopsis. Plant Physiol 160:178-191

Kwon K, Choi D, Hyun JK, Jung HS, Baek K, Park C (2013) Novel glyoxalases from Arabidopsis thaliana. FEBS J 280:3328-3339

Lal NK, Nagalakshmi U, Hurlburt NK, Flores R, Bak A, Sone P, Ma X, Song G, Walley J, Shan L, He P, Casteel C, Fisher AJ, DineshKumar SP (2018) The receptor-like cytoplasmic kinase BIK1 localizes to the nucleus and regulates defense hormone expression during plant innate immunity. Cell Host Microbe 23:485-497 
Lamesch P, Berardini TZ, Li D, Swarbreck D, Wilks C, Sasidharan R, Muller R, Dreher K, Alexander DL, Garcia-Hernandez M, Karthikeyan AS, Lee CH, Nelson WD, Ploetz L, Singh S, Wensel A, Huala E (2012) The Arabidopsis information resource (TAIR): improved gene annotation and new tools. Nucleic Acids Res 40:D1202-1210

Lebel E, Heifetz P, Thorne L, Uknes S, Ryals J, Ward E (1998) Functional analysis of regulatory sequences controlling PR-1 gene expression in Arabidopsis. Plant J 16:223-233

Lehmeyer M, Kanofsky K, Hanko EK, Ahrendt S, Wehrs M, Machens F, Hehl R (2016) Functional dissection of a strong and specific microbe-associated molecular pattern-responsive synthetic promoter. Plant Biotechnol J 14:61-71

Lescot M, Dehais P, Thijs G, Marchal K, Moreau Y, Van de Peer Y, Rouze P, Rombauts S (2002) PlantCARE, a database of plant cis-acting regulatory elements and a portal to tools for in silico analysis of promoter sequences. Nucleic Acids Res 30:325-327

Lin J, Nazarenus TJ, Frey JL, Liang X, Wilson MA, Stone JM (2011) A plant DJ-1 homolog is essential for Arabidopsis thaliana chloroplast development. PLoS One 6:e23731

Liu X, Brutlag DL, Liu JS (2001) BioProspector: discovering conserved DNA motifs in upstream regulatory regions of coexpressed genes. Pac Symp Biocomput 2001:127-138

Locci F, Benedetti M, Pontiggia D, Citterico M, Caprari C, Mattei B, Cervone F, De Lorenzo G (2019) An Arabidopsis berberine bridge enzyme-like protein specifically oxidizes cellulose oligomers and plays a role in immunity. Plant J 98:540-554

Machens F, Becker M, Umrath F, Hehl R (2014) Identification of a novel type of WRKY transcription factor binding site in elicitorresponsive cis-sequences from Arabidopsis thaliana. Plant Mol Biol 84:371-385

Mahony S, Benos PV (2007) STAMP: a web tool for exploring DNAbinding motif similarities. Nucleic Acids Res 35:W253-258

Maleck K, Levine A, Eulgem T, Morgan A, Schmid J, Lawton KA, Dangl JL, Dietrich RA (2000) The transcriptome of Arabidopsis thaliana during systemic acquired resistance. Nat Genet 26:403-410

Matys V, Fricke E, Geffers R, Gossling E, Haubrock M, Hehl R, Hornischer K, Karas D, Kel AE, Kel-Margoulis OV, Kloos DU, Land S, Lewicki-Potapov B, Michael H, Münch R, Reuter I, Rotert S, Saxel H, Scheer M, Thiele S, Wingender E (2003) TRANSFAC: transcriptional regulation, from patterns to profiles. Nucleic Acids Res 31:374-378

Mitsuda N, Ikeda M, Takada S, Takiguchi Y, Kondou Y, Yoshizumi T, Fujita M, Shinozaki K, Matsui M, Ohme-Takagi M (2010) Efficient yeast one-/two-hybrid screening using a library composed only of transcription factors in Arabidopsis thaliana. Plant Cell Physiol 51:2145-2151

Nagakubo D, Taira T, Kitaura H, Ikeda M, Tamai K, Iguchi-Ariga SM, Ariga H (1997) DJ-1, a novel oncogene which transforms mouse NIH3T3 cells in cooperation with ras. Biochem Biophys Res Commun 231:509-513

Nürnberger T, Nennstiel D, Jabs T, Sacks WR, Hahlbrock K, Scheel D (1994) High affinity binding of a fungal oligopeptide elicitor to parsley plasma membranes triggers multiple defense responses. Cell 78:449-460

O'Malley RC, Huang SS, Song L, Lewsey MG, Bartlett A, Nery JR, Galli M, Gallavotti A, Ecker JR (2016) Cistrome and epicistrome features shape the regulatory DNA landscape. Cell 165:1280-1292

Perez-Rodriguez P, Riano-Pachon DM, Correa LG, Rensing SA, Kersten B, Mueller-Roeber B (2010) PlnTFDB: updated content and new features of the plant transcription factor database. Nucleic Acids Res 38:D822-827

Perez-Salamo I, Papdi C, Rigo G, Zsigmond L, Vilela B, Lumbreras V, Nagy I, Horvath B, Domoki M, Darula Z, Medzihradszky
K, Bogre L, Koncz C, Szabados L (2014) The heat shock factor A4A confers salt tolerance and is regulated by oxidative stress and the mitogen-activated protein kinases MPK3 and MPK6. Plant Physiol 165:319-334

Rinerson CI, Rabara RC, Tripathi P, Shen QJ, Rushton PJ (2015) The evolution of WRKY transcription factors. BMC Plant Biol 15:66

Rushton PJ, Somssich IE (1998) Transcriptional control of plant genes responsive to pathogens. Curr Opin Plant Biol 1:311-315

Rushton PJ, Torres JT, Parniske M, Wernert P, Hahlbrock K, Somssich IE (1996) Interaction of elicitor-induced DNA-binding proteins with elicitor response elements in the promoters of parsley PR1 genes. EMBO J 15:5690-5700

Rushton PJ, Reinstadler A, Lipka V, Lippok B, Somssich IE (2002) Synthetic plant promoters containing defined regulatory elements provide novel insights into pathogen- and wound-induced signaling. Plant Cell 14:749-762

Rushton PJ, Somssich IE, Ringler P, Shen QJ (2010) WRKY transcription factors. Trends Plant Sci 15:247-258

Sabetta W, Vandelle E, Locato V, Costa A, Cimini S, Bittencourt Moura A, Luoni L, Graf A, Viggiano L, De Gara L, Bellin D, Blanco E, de Pinto MC (2019) Genetic buffering of cyclic AMP in Arabidopsis thaliana compromises the plant immune response triggered by an avirulent strain of Pseudomonas syringae pv. tomato. Plant J 98:590-606

Sambrook J, Russell RW (2001) Molecular cloning: a laboratory manual, 3rd edn. Cold Spring Harbor Laboratory Press, Cold Spring Harbor

Scarpeci TE, Zanor MI, Mueller-Roeber B, Valle EM (2013) Overexpression of AtWRKY30 enhances abiotic stress tolerance during early growth stages in Arabidopsis thaliana. Plant Mol Biol 83:265-277

Seo KH, Zhuang N, Cha JY, Son D, Lee KH (2012) Crystallization and preliminary X-ray data analysis of a DJ-1 homologue from Arabidopsis thaliana (AtDJ-1D). Acta Crystallogr Sect F Struct Biol Cryst Commun 68:101-104

Sprenger-Haussels M, Weisshaar B (2000) Transactivation properties of parsley proline-rich bZIP transcription factors. Plant J 22:1-8

Steffens NO, Galuschka C, Schindler M, Bülow L, Hehl R (2004) AthaMap: an online resource for in silico transcription factor binding sites in the Arabidopsis thaliana genome. Nucleic Acids Res 32:D368-372

Taira T, Saito Y, Niki T, Iguchi-Ariga SM, Takahashi K, Ariga H (2004) DJ-1 has a role in antioxidative stress to prevent cell death. EMBO Rep 5:213-218

van de Löcht U, Meier I, Hahlbrock K, Somssich IE (1990) A 125 bp promoter fragment is sufficient for strong elicitor-mediated gene activation in parsley. EMBO J 9:2945-2950

Wei H, Persson S, Mehta T, Srinivasasainagendra V, Chen L, Page GP, Somerville C, Loraine A (2006) Transcriptional coordination of the metabolic network in Arabidopsis. Plant Physiol 142:762-774

Weirauch MT, Yang A, Albu M, Cote AG, Montenegro-Montero A, Drewe P, Najafabadi HS, Lambert SA, Mann I, Cook K, Zheng H, Goity A, van Bakel H, Lozano JC, Galli M, Lewsey MG, Huang E, Mukherjee T, Chen X, Reece-Hoyes JS, Govindarajan S, Shaulsky G, Walhout AJ, Bouget FY, Ratsch G, Larrondo LF, Ecker JR, Hughes TR (2014) Determination and inference of eukaryotic transcription factor sequence specificity. Cell 158:1431-1443

Xu XM, Lin H, Maple J, Bjorkblom B, Alves G, Larsen JP, Moller SG (2010) The Arabidopsis DJ-1a protein confers stress protection through cytosolic SOD activation. J Cell Sci 123:1644-1651

Yilmaz A, Mejia-Guerra MK, Kurz K, Liang X, Welch L, Grotewold E (2011) AGRIS: the Arabidopsis gene regulatory information server, an update. Nucleic Acids Res 39:D1118-1122

Yoshida S, Ito M, Nishida I, Watanabe A (2001) Isolation and RNA gel blot analysis of genes that could serve as potential molecular 
markers for leaf senescence in Arabidopsis thaliana. Plant Cell Physiol 42:170-178

Zhou M, Lu Y, Bethke G, Harrison BT, Hatsugai N, Katagiri F, Glazebrook J (2017) WRKY70 prevents axenic activation of plant immunity by direct repression of SARD1. New Phytol 217:700-712

Zimmermann P, Hirsch-Hoffmann M, Hennig L, Gruissem W (2004) GENEVESTIGATOR. Arabidopsis microarray database and analysis toolbox. Plant Physiol 136:2621-2632
Publisher's Note Springer Nature remains neutral with regard to jurisdictional claims in published maps and institutional affiliations. 